\title{
Treinamento Gerencial Relato de uma Experiência
}

\author{
Antonio Telles de Vasconcelos \\ Coordenador de Desenvolvimento Gerencial, da FUNCEP/CEDAM.
}

Prestar assistência às Instituições Públicas, no campo do Desenvolvimento de Recursos Humanos, é um dos objetivos da FUNCEP.

Esta proposta encerra toda uma filosofia de atuação voltada para a qualificação, capacitação e valorização dos servidores públicos contribuindo, assim, para que estes venham a ser os principais personagens do processo de reordenamento das organizações às quais pertencem e, por via de consequêencia, de todo o Setor Público efetivamente voltado e adequado aos anseios e necessidades da sociedade brasileira.

O trabalho, a seguir relatado, ressalta esta evidência. Foi efetivado através do Centro de Desenvolvimento da Administração Pública pela Coordenadoria de Desenvolvimento Gerencial.

Em 19 de fevereiro de 1986, a FUNCEP e o Governo do Estado do Piauí, através de sua Secretaria de Administração, firmaram convênio no campo da cooperação mútua, principalmente para a assistência c exccução de atividades de treinamento, para servidores ocupantes de funçăo de Direção e Assessoramento Superior (DAS) e de Chefias e Assistência de Nível Intermediário (DAI), ou seus respectivos correspondentes.

O prazo de vigência deste convênio foi de 02 (dois) anos, dividindose em dois períodos, nos quais inúmeras atividades foram planejadas e realizadas, através de ações conjuntas, por um grupo de técnicos do CEDAM e do Governo do Estado.

$\mathrm{O}$ esquema gráfico configura o modelo de articulação integrada previamente estabelecido para a Direção Política e que, posteriormente, foi perseguido ao longo do período pelas atividades técnicas. Além dos pro- dutos gerados a cada atividade desenvolvida, buscou-se estimular, em níveis crescentes, a autonomia da Instituição assistida. Igualmente a oportunidade permitiu a captalização de inúmeras experiências que foram vivenciadas pelo quadro técnico do $\mathrm{CE}$ DAM, solidificando e ampliando, assim, sua capacidade e competência profissional de atuar em contextos organizacionais complexos e extremamente diferenciados, como são as organizações públicas dos três níveis do governo, cada uma com suas caracteristicas e especificidades peculiares em termos de cultura, clima, valores, etc. (1)

No total, foram realizados 11 eventos que alcançaram, no conjunto, um universo de 615 servidores de várias categorias funcionais e de vários estados da regiào nordeste. $\mathrm{O}$ número de horas foi de 512. De forma geral, todos tiveram como preocupação central reunir servidores da três esferas de governo criando, assim, condições para uma efetiva proposta de participação integrada, na discussão de temas comuns.

Direção e Assessoramento Superior - DAS:

Em termos de objetivos específicos, os eventos estiveram voltados para os seguintes aspectos:

Análise do papel que cabe a este segmento desempenhar nos contextos organizacionais, principalmente em momentos de mudança acelerada como o atualmente vivenciado pela sociedade brasileira e mais especificamente pela Administração Pública.

Esta análise esteve centrada através dos seguintes aspectos:

- Demandas e expectativas sobre o DAS.

- Mudança e Desenvolvimento.
- Integração Inter e Intra Organizacional.

- Descentralização e racionalidade administrativa.

Este treinamento oferecido em 05 épocas distintas, envolveu ao todo 106 ocupantes destas funções.

Direção e Assistência Intermediária - DAI.

Para este estrato, pela posição que ocupa nas estruturas de poder formal, dentro das orgaizações, direcionou-se treinando para um envolvimento analítico, centrado nas seguintes dimensões:

- O usuário como ponto central e finalístico da Administração Pública.

- O serviço público (condições atuais) e as aspiraçōes e necessidades dos usuários.

Três eventos foram realizados para esta clientela, alcançando um total de 46 servidores.

Seminário de Ações Governamentais Integradas.

Este evento foi um ponto referencial significativo no desencadeamento das ações do Convênio. Marcou o reinicio das atividades que haviam sido interrompidas pela mudança de governo no final de 1986 , ressaltando que as açōes consistentes sobrevivem à transferência de poder, e têm continuidade objetiva. (2)

Em termos de desdobramento, possibilitou aos participantes, oriundos de vários estados tanto da região Norte quanto Nordeste, condições de análise e debates sobre importantes temas para a Administração Pública Brasileira, tais como: Modernização, Descentralização e Recursos Humanos. 


\section{IDÉIAS}

Diversas Instituiçōes e expressivas autoridades das áreas de modernização, Reforma Administrativa e Recursos Humanos, tanto da administração Federal, como Estadual, fizeram-se presentes e desenvolveram palestras e painéis técnicos.

Representando o Ministro Aluízio Alves, que esteve impossibilitado de comparecer, o Secretário-Geral da SEDAP/PR, professor Gileno Fernandes Marcelino, abriu o evento e logo a seguir proferiu palestra sobre o tema: "A Evolução do Estado e a Modernização Administrativa".

No último dia da programação, o então Diretor-Geral do CEDAM, Dr. João Batista Cascudo Rodrigues que acompanhou o desenvolvimento de todo o Seminário, discorreu sobre o tema: "Recursos Humanos - Funções, Disfunções e Caminhos".

Preparação de Monitores:

Esta atividade foi desencadeada com vistas a preparar um grupo de servidores do estado para posteriormente repassarem um programa especial que o CEDAM estruturou, destinado à atualização gerencial para chefias de nivel operacional.

Este curso, através de uma metodologia diferenciada, foi concebido dentro de uma abordagem praxiológica; com o objetivo de melhorar a atuação do chefe junto à sua equipe, de acordo com as particularidades de seu setor.

Dentro de um modelo açãoreflexão, leva a vivenciar, no grupo de treinamento, as proposiçōes apresentadas no material instrucional, experimentar no seu setor de trabalho e voltar a refletir sobre os resultados obtidos.

Num primeiro momento, foram preparados monitores previamente recrutados a partir de um perfil adequado a estas funções.

A segunda etapa da ação dar-se-á pela assistência a esses monitores, quando do repasse da metodologia a chefias operacionais das organizaçōes interessadas.
Nessa metodologia, os monitores atuarão somente como facilitadores, agentes multiplicadores do processo.

Este grupo de monitores, para desempenho de suas atividades, estará ligado ao Instituto de Desenvolvimento de Recursos Humanos, que coordenará este treinamento para servidores do Estado do Piauí.

Esta atividade foi integralmente conduzida por Joaquina Lúcia Calvão Reis, Supervisora do Programa e Norember Alves Campos, Instrutor - ambos do CEDAM/FUNCEP.

Encontro de Dirigentes e Assessores:

Este evento, realizado em 23 de maio passado, foi articulado com dois propósitos distintos, porém intercorrentes.

O primeiro foi o de propiciar um momento de avaliação de todo o processo desenvolvido a longo período. Para tanto, foram convidados a participar todos os servidores envolvidos nos treinamentos realizados tanto pata DAS como DAI. Do universo, que foi de 152 , compareceram ao encontro 81 treinandos. Igualmente, convidou-se a participar do evento
150 outros servidores, detentores de DAS e DAI que não foram envolvidos pelas atividades anteriores. Deste grupo, participaram 116 pessoas.

Esta ação de pesquisa possibilitou a aplicação de um questionário, aos dois grupos, que após sua tabulação permitirá uma interpretação sobre múltiplos aspectos ligados, não só ao treinamento em si, mas também à realidade das organizações às quais pertencem.

Este material, devidamente sistematizado, conterá preciosas informações tanto para o CEDAM/FUNCEP quanto para o IDRH/SEAD/PI.

O segundo grande objetivo do encontro foi o da criação do Instituto de Desenvolvimento de Recursos $\mathrm{Hu}$ manos do governo do Estado do Piauí.

Como última etapa das açōes propostas no programa de ação integrada entre a FUNCEP/CEDAM e a Secretaria de Administração do Governo do Estado, o novo órgão de atuação em DRH é peça importante da política do governo local em valorizar, qualificar e desenvolver os seus servidores públicos.

\begin{tabular}{|c|cc|}
\hline \multicolumn{1}{|c|}{ ATIVIDADES DESENVOLVIDAS } & \\
\hline Participantes & Periodo & carga horária \\
\hline Direção e Assessoramento Superior - DAS & 40 \\
12 & $31 / 03$ a $05 / 04 / 86$ & 40 \\
15 & 05 a $09 / 05 / 86$ & 40 \\
29 & 19 a $23 / 10 / 87$ & 40 \\
17 & 11 a $15 / 01 / 88$ & 40 \\
19 & 14 a $18 / 03 / 88$ & 40 \\
Direção e Assistência Intermediária - DAI & 40 \\
21 & 05 a $09 / 05 / 86$ & \\
10 & 11 a $15 / 01 / 88$ & \\
15 & 14 a $18 / 03 / 88$ & 24 \\
Seminário de Ações Governamentais Integradas & \\
235 & $31 / 07$ a $02 / 09 / 87$ & \\
Atualização Gerencial para Chefias de Nivel Operacional & \\
(Preparação de Monitores) & $23 / 05 / 88$ & \\
09 & $19 / 10 / 87$ a $18 / 03 / 88$ & \\
Encontro de Dirigentes e de Assessores & \\
219 & & \\
\hline
\end{tabular}




\section{IDÉIAS}

A importância das ações decorrentes destas atividades, para todas as partes envolvidas, transcedem em muito ao que consta deste relato.

Especificamente, para os técnicos da Coordenadoria de Desenvolvimento Gerencial, a experiência vivenciada apresentou-se como um desafio e uma excelente oportunidade de meIhor compreensão de múltiplos fenômenos organizacionais a nível de administração pública, assim como da incorporação e sedimentação de melhores e mais abrangentes conhecimentos.

A Administração Pública, nesse momento de transição democrática, tem um novo e importante papel a cumprir, quer como executante das políticas de governo no campo do planejamento governamental normativo, quer como prestadora de serviços a um público usuário que cada. vez mais toma consciência de seus direitos.

Para tal, a dimensão Recursos Humanos assume a concretude de sua importância e do seu significado. Meio e fim, num processo que, por vezes, torna-se extremamente dificil estabelecer limites. Única via, no entanto, para a efetivação das mudanças pretendidas. Afinal, sabemos que não existe organização ou socicdade mais desenvolvida que os seus recursos humanos. São estes que podem acelerar ou entravar o processo de desenvolvimento organizacional e societário.

A nivel de Serviço Público, começa por obter-se gerências capazes, qualificadas e motivadas, base indispensável para toda uma atuação mais consistente e determinada e da qual emerge uma nova forma de pensar e de agir, primeiramente mais sistematizada, comprometida e responsável, nestes estratos de poder e, dai, repercutindo para todos os demais componentes das Instituições.
ARTICULAÇ̊O INTERINSTITUCIONAL INTEGRADA

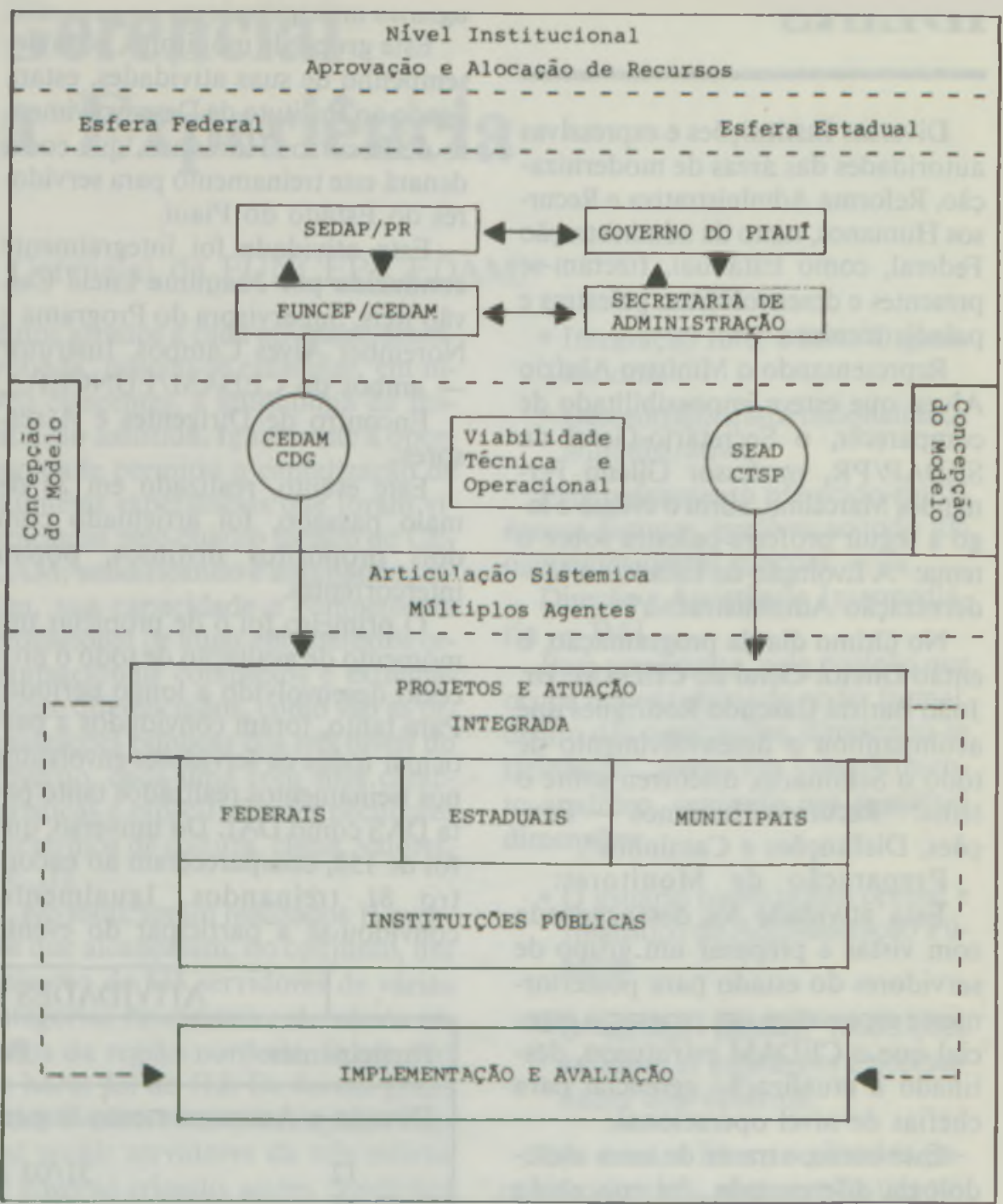

(1)

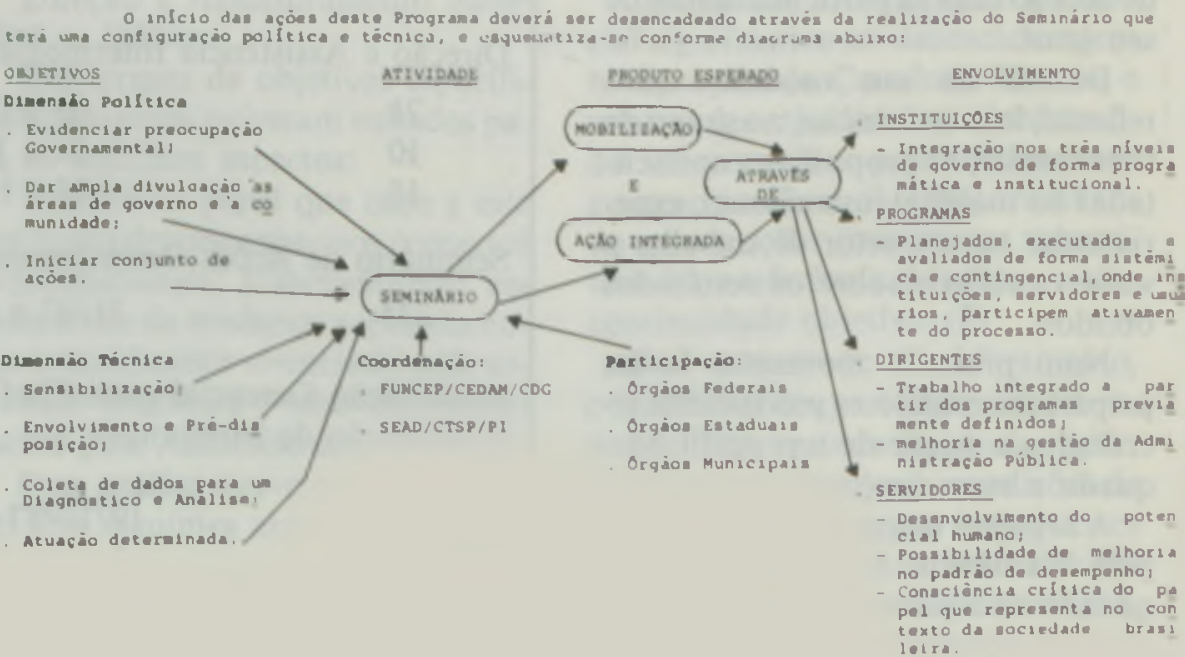

